\title{
Evaluation of damages caused by slugs (Gastropoda: Arionidae, Agriolimacidae) to selected agricultural plants
}

\section{Ocena uszkodzeń wybranych roślin rolniczych powodowanych przez ślimaki nagie (Gastropoda: Arionidae, Agriolimacidae)}

\author{
Jan Kozłowski ${ }^{1 *}$, Monika Jaskulska $^{1}$, Maria Kozłowska ${ }^{2}$
}

\section{Summary}

Slugs present a serious threat to many species of cultivated plants. Recently, more damage has been observed in minor crops, mainly Fabaceae family. In order to investigate of plants from this family susceptibility to various species of slugs, we performed laboratory tests assessing the degree of damage caused by Arion vulgaris, Arion rufus and Deroceras reticulatum to six plant species. We determined the extent of plant damage during seven days of slug grazing in no-choice tests. Significant differences were found among the plant and slug species included in the study. Common vetch and serradella were more susceptible to damage caused by A. vulgaris and $A$. rufus, while white sweet clover and red clover sustained more damage from $D$. reticulatum.

Key words: slugs; selected plant species; damage

\section{Streszczenie}

Ślimaki nagie stanowią poważne zagrożenie dla wielu gatunków roślin uprawnych. Ostatnio coraz częściej obserwuje się szkody w uprawach małoobszarowych, głównie na roślinach z rodziny Fabaceae. W celu oceny ich podatności na różne gatunki ślimaków, w warunkach laboratoryjnych wykonano badania nad stopniem uszkodzenia sześciu gatunków roślin przez ślimaki Arion vulgaris, Arion rufus i Deroceras reticulatum. W testach bez wyboru oceniano wielkość uszkodzeń roślin podczas siedmiu dni żerowania ślimaków. Stwierdzono znaczne zróżnicowanie pomiędzy badanymi gatunkami roślin i gatunkami ślimaków. Wyższą podatność na uszkodzenia przez $A$. vulgaris i $A$. rufus wykazały wyka siewna i seradela siewna, a na $D$. reticulatum nostrzyk biały i koniczyna czerwona.

Słowa kluczowe: ślimaki nagie; wybrane gatunki roślin; uszkodzenia

\footnotetext{
Instytut Ochrony Roślin - Państwowy Instytut Badawczy

Władysława Węgorka 20, 60-318 Poznań

${ }^{2}$ Uniwersytet Przyrodniczy w Poznaniu

Wojska Polskiego 28, 60-637 Poznań

*corresponding author: j.kozlowski@iorpib.poznan.pl
} 


\section{Wstęp / Introduction}

W ostatnich latach prowadzone są intensywne badania nad ochroną upraw małoobszarowych przed agrofagami. Wśród roślin uprawianych na małych powierzchniach dużą grupę stanowią rośliny z rodziny bobowatych (Fabaceae), między innymi: wyka siewna, seradela siewna, koniczyna czerwona, nostrzyk biały oraz rośliny z rodziny ogórecznikowatych (Boraginaceae) - facelia błękitna i kapustowatych (Brassicaceae) - gorczyca biała. Rośliny te są uprawiane w celach paszowych, nawozowych oraz poprawiających strukturę gleby i dostarczają cennego pyłku pszczołom, trzmielom i innym zapylaczom. Ślimaki to szkodniki wielożerne, powodujace uszkodzenia wielu gatunków roślin rolniczych i ozdobnych oraz warzyw (Glen i Moens 2002; Moens i Glen 2002; Port i Ester 2002; Kozłowski 2012). Największe szkody o znaczeniu ekonomicznym powodują: ślinik pospolity - Arion vulgaris Moquin Tandon (nazywany wcześniej Arion lusitanicus Mabille), ślinik wielki - Arion rufus (Linnaeus) i pomrowik plamisty - Deroceras reticulatum (O.F. Müller). Ślimaki te uszkadzają rośliny we wszystkich fazach ich rozwoju, jednak największe straty powodują niszcząc siewki i młode rośliny. Dotychczasowe badania wskazują, że poziom uszkodzeń poszczególnych gatunków roślin przez ślimaki jest zróżnicowany. Wynika to $\mathrm{z}$ ich różnych fizycznych i biochemicznych właściwości, które mają wpływ na aktywność żerowania ślimaków na roślinach. Fakt ten może być wykorzystany w integrowanej ochronie roślin przed szkodliwymi ślimakami. Konieczne jest jednak ustalenie stopnia uszkodzenia poszczególnych gatunków roślin przez różne gatunki ślimaków. Informacje na ten temat dotyczą tylko nielicznych gatunków roślin rolniczych i zielarskich (Hanley i wsp. 1995; Briner i Frank 1998; Frank 1998; Kozłowski i Kozłowska 2009; Kozłowski i wsp. 2013). Brak jest natomiast danych dotyczących stopnia uszkodzeń wymienionych powyżej gatunków roślin, co było powodem podjęcia niniejszych badań.

Celem badań było określenie podatności wybranych gatunków roślin na żerowanie ślimaków A. vulgaris, A. rufus i $D$. reticulatum.

\section{Materiały i metody I Materials and methods}

W warunkach laboratoryjnych wykonano testy z wyborem na roślinach: facelii błękitnej (Phacelia tanacetifolia Benth.), gorczycy białej (Sinapis alba L.), koniczyny czerwonej (Trifolium pratense L.), nostrzyka białego (Melilotus albus L.), seradeli siewnej (Ornithopus sativus L.) i wyki siewnej (Vicia sativa L.), które eksponowano na żerowanie ślinika pospolitego (A. vulgaris), ślinika wielkiego (A. rufus) i pomrowika plamistego (D. reticulatum). Ślimaki w wieku około czterech miesięcy, zebrane $\mathrm{z}$ różnych upraw ogrodniczych (truskawka, malina, rośliny kwiatowe) z okolic Poznania i Wronek, trzymano w plastikowych pojemnikach, na podłożu wilgotnej ziemi, w temperaturze $17^{\circ} \mathrm{C}$ i długości dnia 12 godzin. Trzy razy w tygodniu ślimakom podawano i wymieniano pokarm: liście kapusty, otręby pszenne, mleko w proszku i węglan wapnia. Przed każdym testem ślimaki przez 48 godzin głodzono i po zważeniu wybierano osobniki o zbliżonej masie. Rośliny do doświadczeń, w fazie 3-4 liści, uzyskano $\mathrm{z}$ nasion wysianych $\mathrm{w}$ skrzynkach ogrodniczych, w szklarni Instytutu Ochrony Roślin - Państwowego Instytutu Badawczego w Poznaniu.

Doświadczenia przeprowadzono w układzie o blokach zagnieżdżonych. Rośliny rozmieszczono w kontenerach zgodnie ze schematem rozlosowania obiektów przedstawionym na rysunku 1 . W kontenerach o wymiarach $72 \times 35 \times 15 \mathrm{~cm}$, w $5 \mathrm{~cm}$ warstwie ziemi, posadzono sześć roślin każdego gatunku (po trzy rośliny na dwóch poletkach). Po dwóch dniach w kontenerach umieszczono sześć ślimaków jednego gatunku, o średniej masie: A. vulgaris $1,46 \mathrm{~g}, A$. rufus $1,68 \mathrm{~g}$ i $D$. reticulatum $0,45 \mathrm{~g}$. Testy wykonano w kabinie klimatycznej w temperaturze $17^{\circ} \mathrm{C}$, wilgotności względnej powierza $(\mathrm{RH}) 70 \pm 3 \%$ i przy fotoperiodzie 12/12 godzin (dzień/noc). Raz dziennie określono wielkość uszkodzenia roślin przez ślimaki, według pięciostopniowej skali $(0 ; 25 ; 50 ; 75$ i $100 \%$ uszkodzonej powierzchni roślin). Dla wszystkich gatunków roślin i ślimaków wykonano po sześć powtórzeń. Wyniki poddano analizie wariancji (ANOVA), a różnice oceniano za pomocą testu Fishera przy poziomie istotności $\alpha=0,05$. W celu sklasyfikowania gatunków roślin pod względem wielkości uszkodzeń przez trzy gatunki ślimaków przeprowadzono analizę skupień dla piątego dnia obserwacji (STATISTICA v. 12).

\begin{tabular}{|l|l|l||l|l|l|}
\hline 1 & 4 & 2 & 5 & 2 & 6 \\
\hline 5 & 3 & 6 & 3 & 1 & 4 \\
\hline
\end{tabular}

\begin{tabular}{|l|l|l||l|l|l||}
\hline 3 & 6 & 4 & 6 & 3 & 1 \\
\hline 1 & 5 & 2 & 4 & 2 & 5 \\
\hline \hline 4 & 1 & 5 & 2 & 5 & 3 \\
\hline 2 & 6 & 3 & 6 & 4 & 1 \\
\hline \hline
\end{tabular}

Rys. 1. Schemat rozlosowania obiektów: 1) facelia błękitna (Stala), 2) gorczyca biała (Maryna), 3) nostrzyk biały (Adela), 4) wyka siewna (Hanka), 5) seradela siewna (Bydgoska), 6) koniczyna czerwona (Rozeta)

Fig. 1. Object allocation layout: 1) phacelia (Stala), 2) white mustard (Maryna), 3) white melilot (Adela), 4) common vetch (Hanka), 5) serradella (Bydgoska), 6) red clover (Rozeta)

\section{Wyniki i dyskusja / Results and discussion}

Pierwsze istotne różnice $\mathrm{w}$ wielkości uszkodzeń roślin przez A. vulgaris wystąpiły po dwóch dniach żerowania ślimaków (tab. 1). Silniej uszkodzone były rośliny wyki siewnej i seradeli siewnej w porównaniu do roślin facelii błękitnej, gorczycy białej i koniczyny czerwonej. Po sześciu dniach rośliny seradeli siewnej i koniczyny czerwonej były uszkodzone w $100 \%$, a rośliny wyki siewnej i nostrzyka białego w 98,6\%. Istotnie słabiej uszkodzone były rośliny facelii błękitnej $(81,9 \%)$ i gorczycy białej (87,5\%). Podczas sześciu dni żerowania największe róż- 
Tabela 1. Uszkodzenia różnych gatunków roślin [\%] przez Arion vulgaris i wyniki testu Fishera przy poziomie istotności $\alpha=0,05$

Table 1. Damages caused by Arion vulgaris to different plant species [\%] and the results of Fisher's test at a significance level $\alpha=0.05$

\begin{tabular}{l|c|c|c|c|c|c|c}
\hline \multirow{2}{*}{\multicolumn{1}{c}{ Gatunek rośliny - Plant species }} & \multicolumn{7}{c}{ Dni żerowania ślimaków - Days of slugs feeding } \\
\cline { 2 - 9 } & 1 & 2 & 3 & 4 & 5 & 6 & 7 \\
\hline Facelia błękitna - Phacelia tanacetifolia & $26,4 \mathrm{a}$ & $41,7 \mathrm{a}$ & $55,6 \mathrm{a}$ & $61,1 \mathrm{a}$ & $76,4 \mathrm{a}$ & $81,9 \mathrm{a}$ & $86,1 \mathrm{a}$ \\
\hline Gorczyca biała - Sinapis alba & $26,4 \mathrm{a}$ & $40,3 \mathrm{a}$ & $54,2 \mathrm{a}$ & $62,5 \mathrm{a}$ & $75,0 \mathrm{a}$ & $87,5 \mathrm{a}$ & $94,4 \mathrm{~b}$ \\
\hline Koniczyna czerwona - Trifolium pratense & $26,4 \mathrm{a}$ & $43,1 \mathrm{a}$ & $61,1 \mathrm{ab}$ & $70,8 \mathrm{a}$ & $91,7 \mathrm{~b}$ & $100,0 \mathrm{~b}$ & $100,0 \mathrm{~b}$ \\
\hline Nostrzyk biały - Melilotus albus & $33,3 \mathrm{a}$ & $51,4 \mathrm{ab}$ & $73,6 \mathrm{bc}$ & $87,5 \mathrm{~b}$ & $95,8 \mathrm{~b}$ & $98,6 \mathrm{~b}$ & $100,0 \mathrm{~b}$ \\
\hline Seradela siewna - Ornithopus sativus & $40,3 \mathrm{a}$ & $62,5 \mathrm{~b}$ & $86,1 \mathrm{c}$ & $93,1 \mathrm{~b}$ & $97,2 \mathrm{~b}$ & $100,0 \mathrm{~b}$ & $100,0 \mathrm{~b}$ \\
\hline Wyka siewna - Vicia sativa & $45,8 \mathrm{a}$ & $61,1 \mathrm{~b}$ & $79,2 \mathrm{c}$ & $93,1 \mathrm{~b}$ & $94,4 \mathrm{~b}$ & $98,6 \mathrm{~b}$ & $100,0 \mathrm{~b}$ \\
\hline
\end{tabular}

Wartości w kolumnach oznaczone, co najmniej jedną taką samą literą nie różnią się istotnie

Values in columns marked with at least the same letter do not differ significantly

Tabela 2. Uszkodzenia różnych gatunków roślin [\%] przez Arion rufus i wyniki testu Fishera przy poziomie istotności $\alpha=0,05$

Table 2. Damages caused by Arion rufus to different plant species [\%] and the results of Fisher's test at a significance level $\alpha=0.05$

\begin{tabular}{l|c|c|c|c|c|c|c}
\hline \multirow{2}{*}{\multicolumn{1}{c}{ Gatunek rośliny - Plant species }} & \multicolumn{7}{c}{ Dni żerowania ślimaków - Days of slugs feeding } \\
\cline { 2 - 9 } & 1 & 2 & 3 & 4 & 5 & 6 & 7 \\
\hline Facelia błękitna - Phacelia tanacetifolia & $19,4 \mathrm{a}$ & $31,9 \mathrm{ab}$ & $41,7 \mathrm{~b}$ & $48,6 \mathrm{bc}$ & $58,3 \mathrm{bc}$ & $66,7 \mathrm{bc}$ & $73,6 \mathrm{bc}$ \\
\hline Gorczyca biała - Sinapis alba & $29,2 \mathrm{a}$ & $45,8 \mathrm{bc}$ & $50,0 \mathrm{~b}$ & $63,9 \mathrm{c}$ & $75,0 \mathrm{c}$ & $81,9 \mathrm{~cd}$ & $84,7 \mathrm{~cd}$ \\
\hline Koniczyna czerwona - Trifolium pratense & $12,5 \mathrm{a}$ & $12,5 \mathrm{a}$ & $16,7 \mathrm{a}$ & $19,4 \mathrm{a}$ & $22,2 \mathrm{a}$ & $26,4 \mathrm{a}$ & $31,9 \mathrm{a}$ \\
\hline Nostrzyk biały - Melilotus albus & $16,7 \mathrm{a}$ & $30,6 \mathrm{ab}$ & $38,9 \mathrm{~b}$ & $45,8 \mathrm{~b}$ & $48,6 \mathrm{~b}$ & $48,6 \mathrm{~b}$ & $54,2 \mathrm{~b}$ \\
\hline Seradela siewna - Ornithopus sativus & $55,6 \mathrm{~b}$ & $63,9 \mathrm{c}$ & $80,6 \mathrm{c}$ & $80,6 \mathrm{~cd}$ & $94,4 \mathrm{~d}$ & $94,4 \mathrm{~d}$ & $94,4 \mathrm{~d}$ \\
\hline Wyka siewna - Vicia sativa & $23,6 \mathrm{a}$ & $50,0 \mathrm{bc}$ & $72,2 \mathrm{c}$ & $88,9 \mathrm{~d}$ & $93,1 \mathrm{~d}$ & $95,8 \mathrm{~d}$ & $98,6 \mathrm{~d}$ \\
\hline
\end{tabular}

Wartości w kolumnach oznaczone, co najmniej jedną taką samą literą nie różnią się istotnie

Values in columns marked with at least the same letter do not differ significantly

Tabela 3. Uszkodzenia różnych gatunków roślin [\%] przez Deroceras reticulatum i wyniki testu Fishera przy poziomie istotności $\alpha=0,05$

Table 3. Damages caused by Deroceras reticulatum to different plant species [\%] and the results of Fisher's test at a significance level $\alpha=0.05$

\begin{tabular}{l|c|c|c|c|c|c|c}
\hline \multirow{2}{*}{\multicolumn{1}{c}{ Gatunek rośliny - Plant species }} & \multicolumn{7}{c}{ Dni żerowania ślimaków - Days of slugs feeding } \\
\cline { 2 - 8 } & 1 & 2 & 3 & 4 & 5 & 6 & 7 \\
\hline Facelia błękitna - Phacelia tanacetifolia & $8,3 \mathrm{a}$ & $13,9 \mathrm{a}$ & $25,0 \mathrm{a}$ & $27,8 \mathrm{a}$ & $38,9 \mathrm{a}$ & $44,4 \mathrm{ab}$ & $55,6 \mathrm{~b}$ \\
\hline Gorczyca biała - Sinapis alba & $16,7 \mathrm{ab}$ & $19,4 \mathrm{a}$ & $22,2 \mathrm{a}$ & $22,2 \mathrm{a}$ & $29,2 \mathrm{a}$ & $30,6 \mathrm{a}$ & $34,7 \mathrm{a}$ \\
\hline Koniczyna czerwona - Trifolium pratense & $27,8 \mathrm{bc}$ & $40,3 \mathrm{~b}$ & $61,1 \mathrm{bc}$ & $66,7 \mathrm{~cd}$ & $75,0 \mathrm{~cd}$ & $83,3 \mathrm{c}$ & $88,9 \mathrm{c}$ \\
\hline Nostrzyk biały - Melilotus albus & $38,9 \mathrm{c}$ & $52,8 \mathrm{~b}$ & $70,8 \mathrm{c}$ & $84,7 \mathrm{~d}$ & $87,5 \mathrm{~d}$ & $93,1 \mathrm{c}$ & $95,8 \mathrm{c}$ \\
\hline Seradela siewna - Ornithopus sativus & $6,9 \mathrm{a}$ & $16,7 \mathrm{a}$ & $26,4 \mathrm{a}$ & $38,9 \mathrm{ab}$ & $44,4 \mathrm{ab}$ & $52,8 \mathrm{~b}$ & $81,9 \mathrm{c}$ \\
\hline Wyka siewna - Vicia sativa & $34,7 \mathrm{c}$ & $43,1 \mathrm{~b}$ & $52,8 \mathrm{~b}$ & $56,9 \mathrm{bc}$ & $62,5 \mathrm{bc}$ & $73,6 \mathrm{c}$ & $83,3 \mathrm{c}$ \\
\hline
\end{tabular}

Wartości w kolumnach oznaczone, co najmniej jedną taką samą literą nie różnią się istotnie

Values in columns marked with at least the same letter do not differ significantly

nice w wielkościach uszkodzeń przez A. vulgaris wystąpiły pomiędzy roślinami seradeli siewnej i facelii błękitnej.

W przypadku A. rufus różnice w wielkościach uszkodzeń roślin badanych gatunków zaobserwowano już po 24 godzinach żerowania ślimaków (tab. 2). Istotnie silniej uszkodzone były rośliny seradeli siewnej w porównaniu do pozostałych roślin. Znacznie większe różnice ujawniły się po dwóch dniach. Stwierdzono większe uszkodzenie roślin seradeli siewnej, wyki siewnej i gorczycy białej w porównaniu do roślin koniczyny czerwonej. Po siedmiu dniach rośliny seradeli siewnej, wyki siewnej i gorczycy białej były istotnie silniej uszkodzone (84,7-98,6\%) niż rośliny koniczyny czerwonej $(31,9 \%)$ i nostrzyka białego $(54,2 \%)$. Największe różnice zaobserwowano pomiędzy wielkością uszkodzeń seradeli siewnej $(94,4 \%)$ i koniczyny czerwonej (31,9\%).

Ślimaki $D$. reticulatum po jednym dniu żerowania istotnie silniej uszkodziły rośliny wyki siewnej, koniczyny czerwonej i nostrzyka białego niż rośliny facelii błękitnej i seradeli siewnej (tab. 3). Od trzeciego do siódmego dnia, istotnie silniej uszkodzone były rośliny koniczyny czerwonej i nostrzyka białego w porównaniu do roślin facelii 
błękitnej, gorczycy białej i seradeli siewnej. Po siedmiu dniach największe uszkodzenia wystąpiły na roślinach nostrzyka białego $(95,8 \%)$, a najmniejsze na roślinach gorczycy białej $(34,7 \%)$. Podczas wszystkich dni oberwacji najsilniej uszkadzane przez $D$. reticulatum były rośliny nostrzyka białego i koniczyny czerwonej, a najsłabiej gorczycy białej i facelii błękitnej.

Analiza skupień dla sześciu gatunków roślin ze względu na ich podatność na żerowanie ślimaków $A$. vulgaris, $A$. rufus i $D$. reticulatum, wyznaczona dla odległości euklidesowej $\mathrm{s}=30$, tworzy trzy skupienia (rys. 2). Wyodrębniono trzy grupy gatunków roślin charakteryzujących się podobną podatnością na żerowanie ślimaków. Do pierwszej grupy należą facelia błękitna i gorczyca biała, do drugiej wyka siewna i seradela siewna, a do trzeciej koniczyna czerwona i nostrzyk biały.

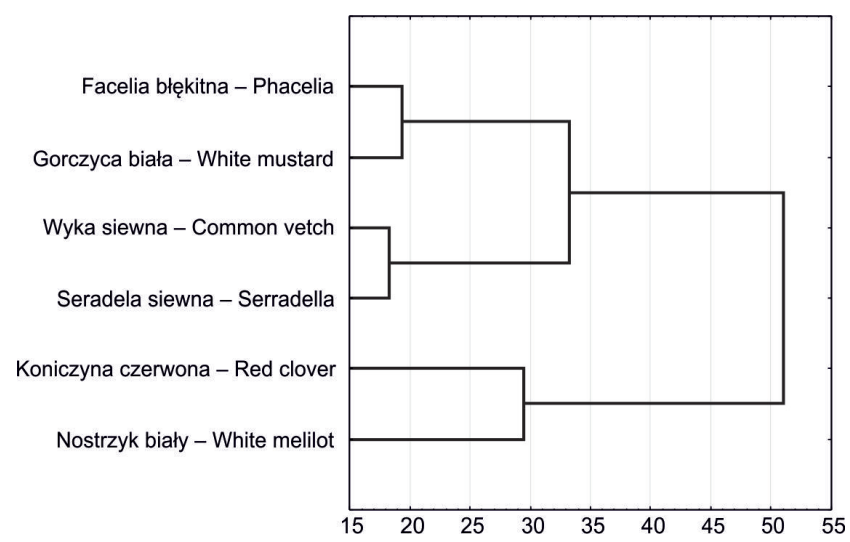

Rys. 2. Analiza skupień dla gatunków roślin pod względem wielkości ich uszkodzeń przez ślimaki Arion vulgaris, Arion rufus i Deroceras reticulatum

Fig. 2. Cluster analysis for plant species in terms of the size of the damage caused by slugs Arion vulgaris, Arion rufus and Deroceras reticulatum

Uzyskane wyniki wskazują, że wielkość uszkodzeń różniła się znacznie dla poszczególnych gatunków roślin i ślimaków. Analiza uszkodzeń roślin przez poszczególne gatunki ślimaków podczas siedmiu dni ich żerowania wykazała, że preferowane przez A. vulgaris i A. rufus były rośliny wyki siewnej i seradeli siewnej, a przez $D$. reticulatum rośliny nostrzyka białego i koniczyny czerwonej. Roślinami słabiej uszkadzanymi przez A. vulgaris i $D$. reticulatum były facelia błękitna i gorczyca biała, a przez A. rufus koniczyna czerwona. Podobne wyniki uzyskano podczas wcześniejszych badań, w których porównywano uszkodzenia szesnastu gatunków roślin (Kozłowski i wsp. 2013). W badaniach tych stwierdzono, że A. vulgaris preferował rośliny wyki siewnej i seradeli siewnej, a $A$. rufus rośliny wyki siewnej. Natomiast słabo uszkadzane przez $D$. reticulatum były rośliny gorczycy białej, a przez A. vulgaris rośliny gorczycy białej i facelii błękitnej (Kozłowski i wsp. 2013). Z badań innych autorów wynika, że roślinami preferowanymi przez $D$. reticulatum są między innymi siewki koniczyny czerwonej i lucerny siewnej [Medicago sativa (L.)] (Briner i Frank 1998; Brooks i wsp. 2003). Frank (1998), badając wpływ A. lusitanicus (= A. vulgaris) i $D$. reticulatum na wzrost różnych gatunków roślin wykazał, że $A$. lusitanicus istotnie ograniczał zagęszczenie maku polnego (Papaver rhoeas L.), natomiast liczebność gorczycy białej po żerowaniu obydwóch gatunków ślimaków pozostawała na tym samym poziomie. Przedstawione wyniki badań dowodzą, że występuje znaczne zróżnicowanie w podatności różnych gatunków roślin na ślimaki. Powstaje pytanie, jakie są tego przyczyny. Jak wiadomo, na wybór pokarmu oraz na aktywność żerowania ślimaków i stopień uszkodzenia roślin mają wpływ morfologiczne i biochemiczne właściwości roślin. Pewną rolę odgrywa struktura liści, głównie owłosienie (Dirzo 1980) oraz zawartość składników odżywczych (Spaull i Eldon 1990). Największe znaczenie mają jednak wtórne metabolity roślinne, które mogą być deterentne lub antyfidalne dla ślimaków. Taki wpływ stwierdzono na przykład dla glukozynolanów występujących w rzepaku (Moens i Glen 2002), alkaloidów w ziemniaku (Ester i Trul 2000) i łubinie (Aguiar i Wink 1999; Kozłowski i wsp. 2017) oraz dla cyjanogennych glikozydów w koniczynie białej (Dirzo i Harper 1982). Dużą rolę w ograniczaniu uszkodzeń roślin przez ślimaki mogą odgrywać także inne substancje roślinne, takie jak: terpenoidy, taniny, fenole, saponiny, flawonoidy i garbniki (Webbe i Lambert 1983; Airey i wsp. 1989; Clark i wsp. 1997), jednak informacje na ten temat są bardzo ubogie. Stwierdzono jedynie, że przy dostępności różnych gatunków czy odmian roślin, ślimaki w pierwszej kolejności wybierają rośliny pozbawione tych związków lub z niską ich zawartością, co powoduje selektywne żerowanie. Dotyczy to zwłaszcza roślin we wczesnych fazach rozwojowych, które są najbardziej wrażliwe na uszkodzenia (Hanley i wsp. 1995; Barlow i wsp. 2013). Uzyskane wyniki sugerują, że niektóre badane rośliny, na przykład facelia błękitna i gorczyca biała mogą zawierać substancje ograniczające żerowanie ślimaków i w rezultacie są słabiej uszkadzane. Informacje te mają znaczenie praktyczne, gdyż mogą być potencjalnie wykorzystane w integrowanych programach ochrony roślin przed ślimakami. Konieczne jest jednak sprawdzenie podatności roślin na ślimaki w warunkach polowych.

\section{Wnioski / Conclusions}

1. Podatność roślin w fazie 3-4 liści, na uszkodzenia przez ślimaki jest zróżnicowana w zależności od gatun$\mathrm{ku}$ rośliny i gatunku ślimaka. Wynika to $\mathrm{z}$ różnych preferencji pokarmowych ślimaków. Bardziej podatne na ślimaki $A$. vulgaris i $A$. rufus były wyka siewna i seradela siewna, a na $D$. reticulatum nostrzyk biały i koniczyna czerwona.

2. Na obszarach zasiedlonych przez ślimaki rośliny podatne na uszkodzenia nie powinny być uprawiane. 


\section{Literatura / References}

Aguiar R., Wink M. 1999. Mollusc-deterrent activity of lupin alkaloids. p. 97-98. In: Proceeding 9th International Lupin Conference. Germany, Klink/Mültriz, 20-24 June 1999. International Lupin Association, Canterbury, New Zeeland, 481 pp.

Airey W.J., Henderson I.F., Pickett J.A., Scott G.C., Stephenson J.W., Woodcock C.M. 1989. Novel chemical approaches to mollusc control. p. 301-307. In: "Slugs and Snails in World Agriculture”, Monograph 41 (I.F. Henderson, ed.). British Crop Protection Council, Thornton Heath.

Barlow S.E., Close A.J., Port G.R. 2013. The acceptability of meadow plants to the slug Deroceras reticulatum and implications for grassland restoration. Annals of Botany 112 (4): 721-730.

Briner T., Frank T. 1998. The palatability of 78 wildflower strip plants to the slug Arion lusitanicus. Annals of Applied Biology 133 (1): 123-133.

Brooks A.S., Crook M.J., Wilcox A., Cook R.T. 2003. A laboratory evaluation of the palatability of legumes to the field slug Deroceras reticulatum Müller. Pest Management Science 59 (3): 245-251.

Clark S.J., Dodds C.J., Henderson I.F., Martin A.P. 1997. A bioassay for screening materials influencing feeding in the field slug Deroceras reticulatum (Müller) (Mollusca, Pulmonata). Annals of Applied Biology 130 (2): 379-385.

Dirzo R. 1980. Experimental studies on slug-plant interactions. I. The acceptability of thirty plant species to the slug Agriolimax caruanae. Journal of Ecology 68 (3): 981-998.

Dirzo R., Harper J.L. 1982. Experimental studies on slug-plant interactions. IV. The performance of cyanogenic and acyanogenic morphs of Trifolium repens in the field. Journal of Ecology 70: 119-138.

Ester A., Trul R. 2000. Slug damage and control of field slug (Deroceras reticulatum (Müller)) by carvone in stored potatoes. Potato Research 43 (3): 253-261.

Frank T. 1998. Slug damage and numbers of the slug pests, Arion lusitanicus and Deroceras reticulatum in oilseed rape grown beside sown wildflower strips. Agriculture, Ecosystems and Environment 67 (1): 67-78.

Glen D.M., Moens R. 2002. Agriolimacidae, Arionidae and Milacidae as pests in West European cereals. p. 271-300. In: "Molluscs as Crop Pests” (G.M. Barker, ed.). Landcare Research Hamilton, New Zealand, CABI Publishing, UK, 468 pp.

Hanley M.E., Fenner M., Edwards P.J. 1995. The effect of seedling age on the likelihood of herbivory by the slug Deroceras reticulatum. Functional Ecology 9: 754-759.

Kozłowski J. 2012. Ślimaki jako przykład nowego i rosnącego zagrożenia. [Slugs as an example of a new and growing threat to crops in Poland]. Progress in Plant Protection/Postępy w Ochronie Roślin 52 (4): 1129-1135.

Kozłowski J., Jaskulska M., Kozłowska M. 2013. Porównanie uszkodzeń różnych gatunków roślin upraw małoobszarowych powodowanych przez ślimaka Arion lusitanicus Mabille. [The comparison of damage caused by the slug Arion lusitanicus Mabille to diferrent plant species of small-area crops]. Progress in Plant Protection/Postępy w Ochronie Roślin 53 (4): 831-834.

Kozłowski J., Jaskulska M., Kozłowska M. 2017. The role alkaloids in the feeding behaviour of slugs (Gastropoda: Stylommatophora) as pests of narrow-leafed lupin plants. Acta Agriculturae Scandinavica, Section B - Soil and Plant Science 67 (3): $263-269$.

Kozłowski J., Kozłowska M. 2009. Palatability and consumption of 95 species of herbaceous plants and oilseed rape for Arion lusitanicus Mabille, 1868. Journal of Conchology 40 (1): 79-90.

Moens R., Glen D.M. 2002. Agriolimacidae, Arionidae and Milacidae as pests in West European oilseed rape. p. 301-314. In: "Molluscs as Crop Pest” (G.M. Barker, ed.). Landcare Research Hamilton, New Zealand, CABI Publishing, UK, 468 pp.

Port R., Ester A. 2002. Gastropods as pests in vegetables and ornamental crops in Western Europe. p. 337-352. In: "Molluscs as Crop Pests” (G.M. Barker, ed.). Landcare Research Hamilton, New Zealand, CABI Publishing, UK, 468 pp.

Spaull A.M., Eldon S. 1990. Is it possible to limit slug damage using choice winter wheat culivars? p. 703-708. In: Proccedings of the Brighton Crop Protection Conference: Pest and Diseases. Vol. 2. UK, Brighton, 17-20 November 1986, 865 pp.

Webbe G., Lambert J.D.H. 1983. Plants that kill snails and prospects for disease control. Nature 302: 754. 